Article

\title{
Biosynthesized Highly Stable Au/C Nanodots: Ideal Probes for the Selective and Sensitive Detection of $\mathrm{Hg}^{2+}$ Ions
}

\author{
Sada Venkateswarlu ${ }^{1,+} \oplus$, Saravanan Govindaraju ${ }^{2,3,+}$, Roopkumar Sangubotla ${ }^{4}$, \\ Jongsung Kim ${ }^{4}\left(\mathbb{D}\right.$, Min-Ho Lee ${ }^{3, * \mathbb{D}}$ and Kyusik Yun ${ }^{2, *}$ \\ 1 Department of Nanochemistry, Gachon University, Gyeonggi-do 13120, Korea; venkisada67@gmail.com \\ 2 Department of Bionanotechnology, Gachon University, Gyeonggi-do 13120, Korea; biovijaysaran@gmail.com \\ 3 School of Integrative Engineering, Chung-Ang University, Seoul 06974, Korea \\ 4 Department of Chemical and Biological Engineering, Gachon University, 1342 Seongnam Daero, \\ Seongnam-Si, Gyeonggi-do 13120, Korea; gachonroop@gmail.com (R.S.); jongkim@gachon.ac.kr (J.K.) \\ * Correspondence: mhlee7@cau.ac.kr (M.-H.L.); ykyusik@gachon.ac.kr (K.Y.); \\ Tel.: +82-02-820-5503 (M.-H.L.); +82-31-750-8753 (K.Y.) \\ + The authors are equally contributed.
}

Received: 23 January 2019; Accepted: 7 February 2019; Published: 12 February 2019

\begin{abstract}
The enormous ongoing industrial development has caused serious water pollution which has become a major crisis, particularly in developing countries. Among the various water pollutants, non-biodegradable heavy metal ions are the most prevalent. Thus, trace-level detection of these metal ions using a simple technique is essential. To address this issue, we have developed a fluorescent probe of $\mathrm{Au} / \mathrm{C}$ nanodots (GCNDs-gold carbon nanodots) using an eco-friendly method based on an extract from waste onion leaves (Allium cepa-red onions). The leaves are rich in many flavonoids, playing a vital role in the formation of GCNDs. Transmission electron microscopy (TEM) and Scanning transmission electron microscopy-Energy-dispersive X-ray spectroscopy (STEM-EDS) elemental mapping clearly indicated that the newly synthesized materials are approximately $2 \mathrm{~nm}$ in size. The resulting GCNDs exhibited a strong orange fluorescence with excitation at $380 \mathrm{~nm}$ and emission at $610 \mathrm{~nm}$. The GCNDs were applied as a fluorescent probe for the detection of $\mathrm{Hg}^{2+}$ ions. They can detect ultra-trace concentrations of $\mathrm{Hg}^{2+}$ with a detection limit of $1.3 \mathrm{nM}$. The X-ray photoelectron spectroscopy results facilitated the identification of a clear detection mechanism. We also used the new probe on a real river water sample. The newly developed sensor is highly stable with a strong fluorescent property and can be used for various applications such as in catalysis and biomedicine.
\end{abstract}

Keywords: onion leaves; GCNDs; orange fluorescent; TEM; mercury ion sensor

\section{Introduction}

Heavy metal ions have caused wide spread water pollution which has become a serious threat to living organisms including humans [1,2]. These heavy metal ions (lead, arsenic, chromium, cadmium, and mercury) mainly enter water systems from various industries [3,4]. Among these pollutants, mercury is one of the most hazardous and is mainly released from electroplating, battery, and coal industries as well as from medical waste and chlor-alkali plants [5,6]. This toxic metal poses health risks which include damage to DNA, the brain, red blood cells, kidneys, and the liver and it is known to compromise the immune system [7,8]. The United States Environmental Protection Agency has set the allowable limit of $\mathrm{Hg}^{2+}$ in drinking water to less than $0.002 \mathrm{mg} / \mathrm{L}$ [9]. Thus, there is an ever-growing demand for sensitive and selective detection of $\mathrm{Hg}^{2+}$ in soil, food, air, and water $[10,11]$. Various techniques have been developed for the detection of $\mathrm{Hg}^{2+}$ ion, including electrochemical and 
colorimetric sensors [12,13]. However, most new techniques are limited in their applications because they have high implementation costs, are difficult to handle, require long sample preparation time, and exhibit low sensitivity and selectivity. Therefore, there is an urgent need to develop a simple method for fast detection of $\mathrm{Hg}^{2+}$. Recently, various fluorescent probes for the detection of $\mathrm{Hg}^{2+}$ ions based on carbon dots (CDs), organic polymers, organic dyes, metal fluorescent nanoparticles, and metal organic frames were reported [14-18].

Among these materials, CDs have unique properties such as strong luminescence, biocompatibility, and high stability. Therefore, CDs have gained considerable research attention for use in biomolecular and heavy metal ion sensing as well as other biological applications [19-21]. In addition, newly developed materials based on the combination of noble metal nanoparticles ( $\mathrm{Au}$ and $\mathrm{Ag}$ ) and CDs possess enhanced optical, photoluminescent, electrochemical, and catalytic properties [22-24]. Specifically, gold clusters can be ultra-small $(<2 \mathrm{~nm})$ and exhibit strong fluorescence, quantized charging, magnetism with good biocompatibility, eco-friendliness, and excellent photostability [25-27]. The oscillation of highly-concentrated free electrons present in gold clusters can considerably enhance the fluorescent property by the interaction between the metallic surface and the host CDs [28-30]. Based on the fluorescent property of gold nanoparticles, the creation of several sensors $(\mathrm{Au} / \mathrm{Ag}, \mathrm{Au} / \mathrm{Cu}$, and dye-encapsulated $\mathrm{Au}$ nanoparticles) for the detection of $\mathrm{Hg}^{2+}$ ions has been reported [31-33]. The reported methods have some disadvantages such as having bimetallic state and toxic dyes which enhance the cost and cause secondary pollution. These disadvantages can be overcome by a careful combination of CDs and Au nanoparticles [8]. Recently, Liu et al. and He et al. reported CDs Au-nanocluster hybrid materials applied as a fluorescent probe for the detection of $\mathrm{Hg}^{2+}$ ions [34,35]. However, these materials were synthesized using expensive, commercially available molecules (L-cysteine, diethylenetriamine, etc.) as the carbon precursors. To overcome these drawbacks, a simple method that uses freely available natural waste materials is required.

Here, we describe the synthesis of uniformly dispersed strongly fluorescent GCNDs using waste onion leaves (Allium cepa-red onions) according to a microwave-assisted method. The annual onion production in South Korea is nearly 1,700,000 metric tons. Onions are the second most cultivated vegetable crop in the world. These are an abundant source of many phytonutrients and phenolic compounds and have excellent antioxidant properties and can protect against various pathologies like cardiovascular and neurological diseases [36]. Various types of onions (white, red, etc.) are available in the world throughout the year; among them, red onions are rich in many flavonoids (quercetin, kaempferol, etc.), polysaccharides (ketose, fructofuranosylnystose, glycoside), anthocyanins, gallic acid, chlorogenic acid, p-coumaric acid, sinapic acid, and other sulfur (thiosulfinates) components etc. $[37,38]$. With many of these compounds having oxygen, nitrogen functional groups are attached to an aromatic and aliphatic carbon skeleton [39]. These biomolecules play a vital role in the formation of nanoparticles by reducing the metallic ions $[40,41]$. Moreover, these onion leaves have several applications in various fields like capacitor etc. [42]. This provides a huge precursor source for the synthesis of carbon dots which can also act as a reducing agent for the formation of gold nanoparticles. The synthesized GCNDs are considerably small $(\sim 2 \mathrm{~nm})$ and give a strong orange fluorescence. Moreover, the biogenic GCNDs are stable for more than seven months. These GCNDs show excellent selectivity and sensitivity towards $\mathrm{Hg}^{2+}$ ions and the mechanisms involved are clearly explained using X-ray photoelectron spectroscopy (XPS) and Fourier-transform infrared spectroscopy (FTIR) techniques. Moreover, these GCNDs may also be useful for biomedical and catalytic applications. Finally, we have performed the reproducibility of the onion leaves extract and GCNDs using several red onions that were cultivated in different areas. 


\section{Materials and Methods}

\subsection{Materials}

Gold (III) chloride trihydrate $\left(\mathrm{HAuCl}_{4} \cdot 3 \mathrm{H}_{2} \mathrm{O}\right)$, L-glutathione $(\mathrm{GSH})$, and mercury nitrate monohydrate $\left(\mathrm{Hg}\left(\mathrm{NO}_{3}\right)_{2} \cdot \mathrm{H}_{2} \mathrm{O}\right)$ were purchased from Sigma-Aldrich (Gyeonggi-do, Seoul, South Korea). The waste red onion leaves were collected from a local market in Seongnam, South Korea. Deionized water was used throughout the experiments.

\subsection{Synthesis of GCNDs}

The GCNDs were synthesized by an extract from red onion leaves. The collected onion leaves were washed with de-ionized water and cut into small pieces. Afterward, $15 \mathrm{~g}$ of pieces were placed into a $250 \mathrm{~mL}$ round bottom flask containing $100 \mathrm{~mL}$ of DI water and were refluxed for $1 \mathrm{~h}$ at $85^{\circ} \mathrm{C}$. The resulting solution was cooled and filtered with cheese cloth. The filtrate was stored for further experiments. A typically and freshly prepared $5 \mathrm{~mL}$ of $30 \mathrm{mM}$ of $\mathrm{HAuCl}_{4} \cdot 3 \mathrm{H}_{2} \mathrm{O}$ aqueous solution and $1 \mathrm{~mL}$ of $75 \mathrm{mM}$ GSH were mixed. The mixture was kept at $80^{\circ} \mathrm{C}$ for $1 \mathrm{~h}$, subsequently $20 \mathrm{~mL}$ of onion leaf extract was added, and the mixture was placed in a microwave oven for $10 \mathrm{~min}$. A pale brown color was obtained by filtration of the reaction mixture. Subsequently, the mixture was dialyzed with a cellulose ester membrane (molecular weight cut-off: $2 \mathrm{kDa}$ ) against DI water for $24 \mathrm{~h}$. Subsequently, powder was obtained by a freeze-drying process. The final product was used for further experiments. Scheme 1 shows an illustration of the formation of GCNDs. Onion extract acts as a reducing agent as well as carbon precursor which will initiate the growth of GCNDs. Moreover, the gold colloidal suspension which contains GSH molecules act as a stabilizing agent to the gold nanodots formation. Finally, the stability of the GCNDs depends on the carbon template which is internally conglomerate with the gold suspension and form stable GCNDs. The tiny gold nanoclusters were homogeneously distributed to the carbon skeleton.

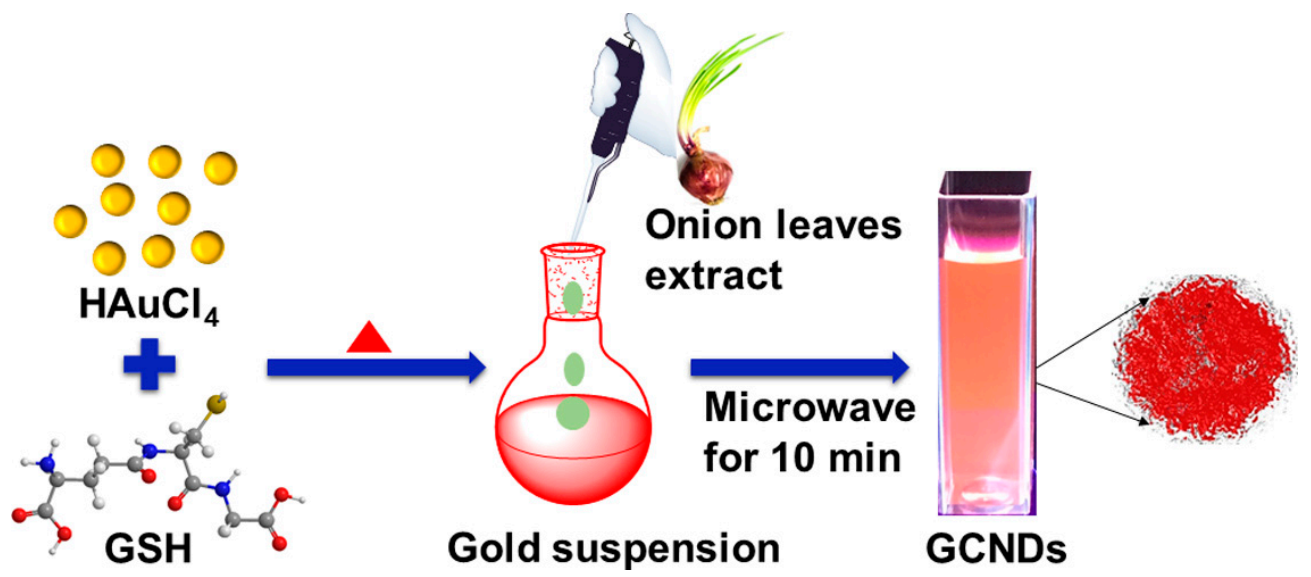

Scheme 1. Biogenic synthesis of GCNDs.

\subsection{Characterization}

Diluted GCNDs samples were examined in dark field images using a PTI UV illuminator (Horiba scientific, Piscataway, NJ, USA) at $365 \mathrm{~nm}$. UV-Vis spectra were measured (Varian Cary 100 UV-Vis spectrophotometer, Palo Alto, CA, USA). The photoluminescence (PL) intensity was recorded by QuantaMaster (Photon Technology International, Birmingham, NJ, USA) which was equipped with a xenon lamp (Arc Lamp Housing, A-1010B ${ }^{\mathrm{TM}}$ ), monochromator and power supply (Brytexbox, NJ, USA). The size and morphological characterization were determined using a JEOL JEM-ARM 200F series TEM instrument (Jeol, Peabody, MA, USA). Atomic force microscopy (AFM) (JPK NanoWizard II bio-atomic force microscope, Berlin, Germany) was performed with a JPK NanoWizard II bioatomic force microscope in contact mode to determine the surface morphology. X-ray diffraction 
(XRD) patterns of the particles were obtained using a Rigaku Rint 2200 Series X-ray Automatic Diffractometer ( $\mathrm{Cu} \mathrm{K} \alpha$ radiation at a wavelength of $1.5406 \AA$ ) (Rigaku Corp., The Woodlands, TX, USA). The GCNDs functional groups were illustrated using FT-IR with a Thermo Nicolet iS-10 spectrometer (BRUKER FT-IR Vertex 70, Billerica, MA, USA) using a $\mathrm{KBr}$ pellet in transmission mode. The detailed composition of the GCNDs was analyzed using a Thermo Scientific (Quanta Master, Photon Technology International, Birmingham, NJ, USA) K-Alpha ${ }^{\mathrm{TM}+}$ (XPS) system equipped with $100-4000 \mathrm{eV}$ range of motion, $180^{\circ}$ double focusing hemispherical analyzer (Thermos scientific, Oklahoma City, OK, USA) with 128-channel detector (Thermos scientific, Oklahoma City, OK, USA), and $\mathrm{Al} \mathrm{Ka}$ micro-focused X-ray source.

\subsection{Detection of $\mathrm{Hg}^{2+}$ Ions Using Fluorescent GCNDs Probe}

For the determination of $\mathrm{Hg}^{2+}$ ions at room temperature, various concentrations of $\mathrm{Hg}^{2+}(0-70 \mu \mathrm{M})$ solution were prepared. A $100 \mu \mathrm{L}$ portion of the prepared $\mathrm{Hg}^{2+}$ solution was added to a cuvette containing $100 \mu \mathrm{L}$ of GCNDs; afterward, a certain volume of PBS (0.1 M, pH 7.5) buffer solution was added to make up a total volume of $2 \mathrm{~mL}$. The reaction mixture was incubated for $5 \mathrm{~min}$ and the PL of the sample was measured with excitation at $380 \mathrm{~nm}$. For investigating the high selectivity of $\mathrm{Hg}^{2+}$, a similar method was applied, however with various interference ions.

\section{Results and Discussion}

\subsection{Material Characterization}

Figure 1a,b show the High-resolution transmission electron microscopy (HRTEM)images of the GCNDs. They are approximately $2 \mathrm{~nm}$ and are uniformly distributed within clusters. In addition, Figure 1c-f shows the STEM-EDS elemental mapping which clearly indicates the presence of elemental $\mathrm{C}, \mathrm{O}$, and $\mathrm{Au}$. The STEM image in Figure 1c clearly indicates the Au/C alloy-type nanoparticles which means that CDs are strongly integrated with the Au clusters. The phase purity is confirmed by the XRD analysis. Figure $1 \mathrm{~h}$ illustrates the XRD pattern with the peaks that appear at $16.9^{\circ}$ and $22.0^{\circ}$ with the plane of (002) corresponding to amorphous carbon and a partially graphitized phase for the CDs. The peaks located at $2 \theta$ values of $38.2^{\circ}$ and $44.1^{\circ}$ refer to the Au present in the form of clusters. Further details of the morphology are shown in the AFM image in Figure 2a which shows uniformly distributed clusters mixed with many tiny GCNDs. The latter are clearly shown in the 3D AFM image in Figure 2b. Moreover, the AFM height profile clearly indicates that the height of the GCNDs is $<4.1 \mathrm{~nm}$. The surface functional groups and composition of GCNDs were analyzed using XPS and FT-IR. The survey scan spectra of GCNDs in Figure 3a(i) show five peaks at 84.2, 163.8, 284, 400, and $530 \mathrm{eV}$ attributed to Au-4f, S-2p, C-1s, N-1s, and O-1s, respectively. After reacting with $\mathrm{Hg}^{2+}$ ions in Figure 3a(ii), the intensities of C-1s and O-1s peaks slightly decreased and S-2p, $\mathrm{N}-1$ s were shifted to a lower binding energy region, which is clearly shown in Figure $3 \mathrm{~d}(\mathrm{ii}), \mathrm{f}(\mathrm{ii})$. Moreover, a new peak appeared at $105 \mathrm{eV}$, which is attributed to the presence of $\mathrm{Hg}^{2+}$, as shown in Figure 3a(ii),g. The high-resolution C-1s spectra of the GCNDs reveal three deconvoluted main peaks at $283.58,289.38$, and $291.78 \mathrm{eV}$ which indicate the presence of $\mathrm{C}-\mathrm{O}, \mathrm{C}=\mathrm{O}$, and $\mathrm{C}-\mathrm{C}$ species, respectively, as shown in Figure 3b. In contrast, the high-resolution O-1s spectrum in Figure 3c reveals two main peaks at 531.08 and $538.58 \mathrm{eV}$, representing $\mathrm{C}-\mathrm{O}$ and $\mathrm{C}=\mathrm{O}$, respectively. Figure $3 \mathrm{~d}$ shows the high-resolution S-2p spectrum with a characteristic peak at $164.5 \mathrm{eV}$, which is attributed to $\mathrm{S}-2 \mathrm{p}-3 / 2$ of -SH groups. Moreover, the high-resolution spectrum of N-1s shows two peaks at 400.5 and $401.8 \mathrm{eV}$, which is attributed to the presence of primary and secondary amine groups, as shown in Figure $3 \mathrm{f}$. A high-resolution spectrum of gold shows peaks at 84.38 and $86.58 \mathrm{eV}$, representing Au-4f-5/2 and $\mathrm{Au}-4 \mathrm{f}-7 / 2$, as shown in Figure 3e [35]. Furthermore, the surface functional groups of the onion leaves extract were analyzed by using FT-IR. Figure 4(i) illustrates a broad peak around $3580 \mathrm{~cm}^{-1}$ which indicates the presence of hydroxyl groups $(-\mathrm{OH})$, and the peak at $2986 \mathrm{~cm}^{-1}$ belongs to the $-\mathrm{CH}$ moiety. Moreover, for the peaks at 1722, 1507, 1426, 1297, 1160, 1065, and $830 \mathrm{~cm}^{-1}$, which are ascribed 
to the carbonyl $(-\mathrm{C}=\mathrm{O})$ group of acids and keto, there are $\mathrm{C}=\mathrm{C},-\mathrm{C}-\mathrm{H},-\mathrm{C}-\mathrm{N}$, $-\mathrm{C}-\mathrm{O}$, and $-\mathrm{C}-\mathrm{S}$ groups of biomolecules (flavonoids, polysaccharides (ketose), anthocyanins, gallic acid, sinapic acid, and thiosulfinates) [43-45]. However, after the formation of GCNDs, the leafy extract peaks almost shifted, as shown in Figure 4(ii) where the peaks appeared at 3513, 3297, 2528, 1753, 1625, and $788 \mathrm{~cm}^{-1}$, which is attributed to the stretching vibrations of $-\mathrm{OH},-\mathrm{NH}_{2} /-\mathrm{NH},-\mathrm{SH}, \mathrm{C}=\mathrm{O}$, amide, and C-S groups, respectively. After treating with $\mathrm{Hg}^{2+}$ ions in Figure 4(iii), the FT-IR peaks at 1753, 1160 are shifted to $1708,1146 \mathrm{~cm}^{-1}$, and the peak at $2528 \mathrm{~cm}^{-1}$ almost disappears, which confirms that $-\mathrm{C}=\mathrm{O},-\mathrm{C}-\mathrm{N}$, and -SH groups are strongly attracted to the target $\mathrm{Hg}^{2+}$ ions. This result indicates the successful formation of leaves extract mediated GSH functionalized GCNDs.
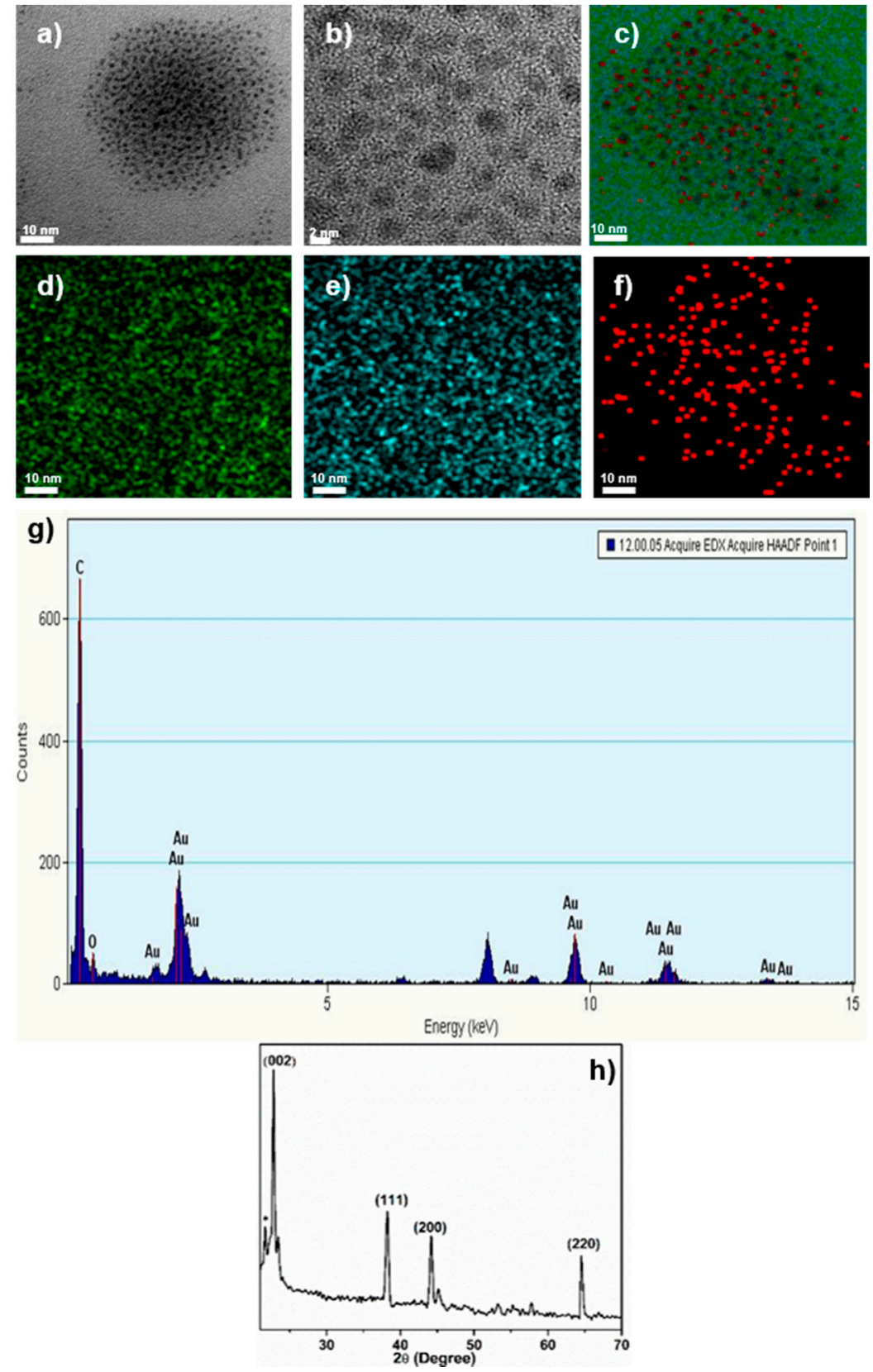

Figure 1. HRTEM, STEM-EDS elemental mapping and XRD (X-ray diffraction) analysis of GCNDs. $(\mathbf{a}, \mathbf{b})$ HRTEM images of GCNDs, (c) STEM image and (d-f) element mapping images of GCNDs, (g) EDS analysis and (h) XRD analysis of GCNDs. 

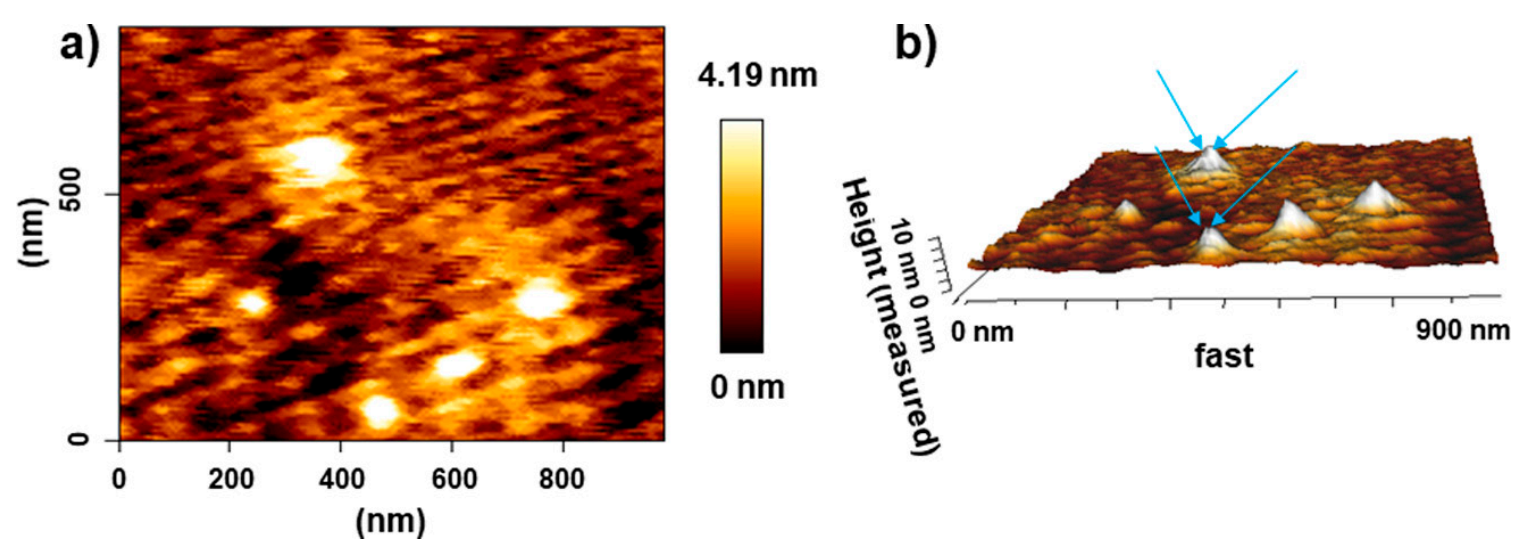

Figure 2. AFM (atomic force microscopy) images of GCNDs. (a) height images of GCNDs. The height of the GCNDs is $4.19 \mathrm{~nm}$. (b) 3D image of GCNDs. The arrow clearly indicates the presence of the GCNDs.
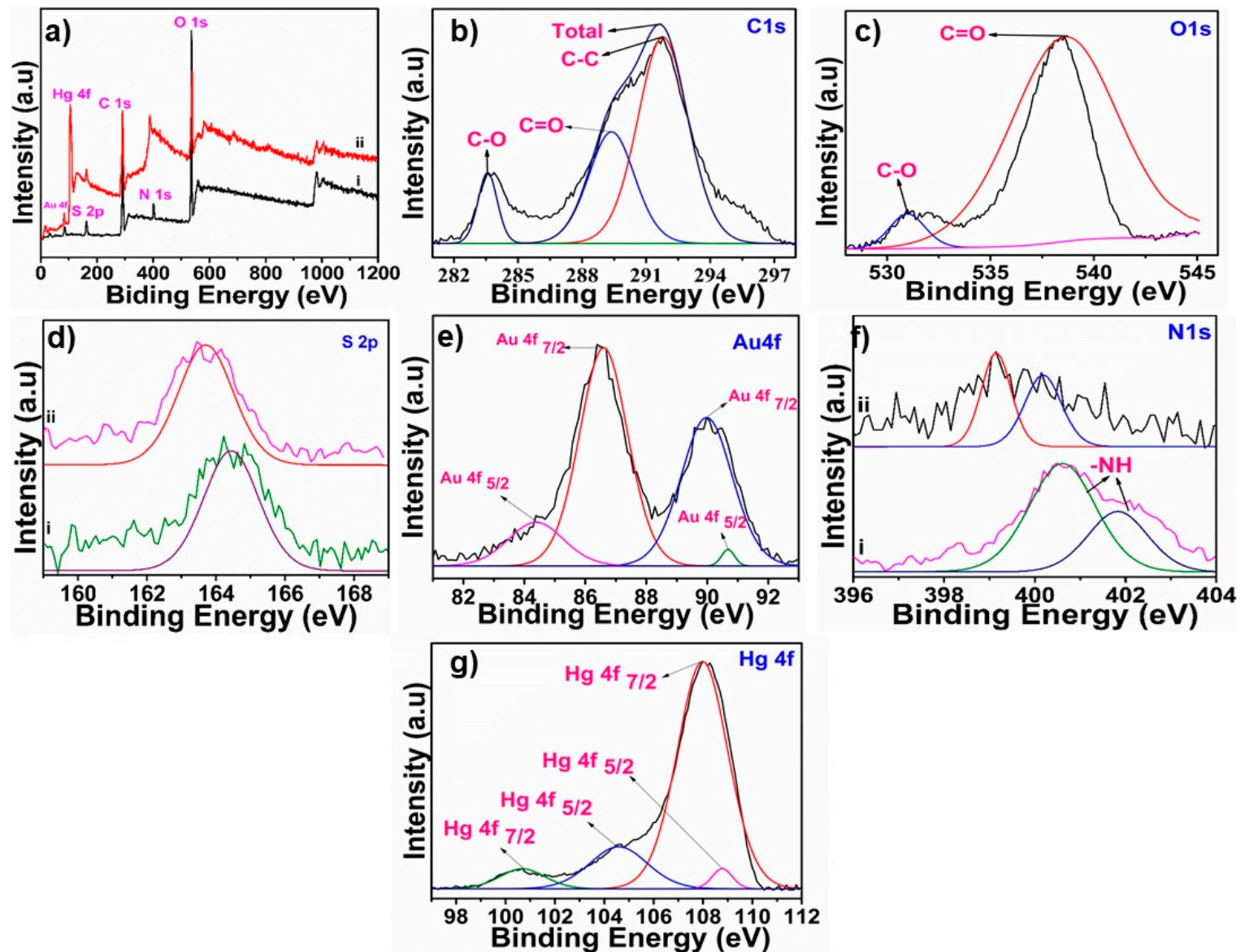

Figure 3. (a) XPS survey scan spectra of GCNDs before (i) and after $\mathrm{Hg}^{2+}$ treatment (ii). (b-g) High resolution XPS spectra of C 1s, O 1s spectrum, S 2p before (i) and after treatment with $\mathrm{Hg}^{2+}$ (ii), Au $4 \mathrm{f}$ spectrum, $\mathrm{N}$ 1s before (i) and after treatment with $\mathrm{Hg}^{2+}$ (ii), and (g) $\mathrm{Hg}^{2+}$ ff spectrum. 


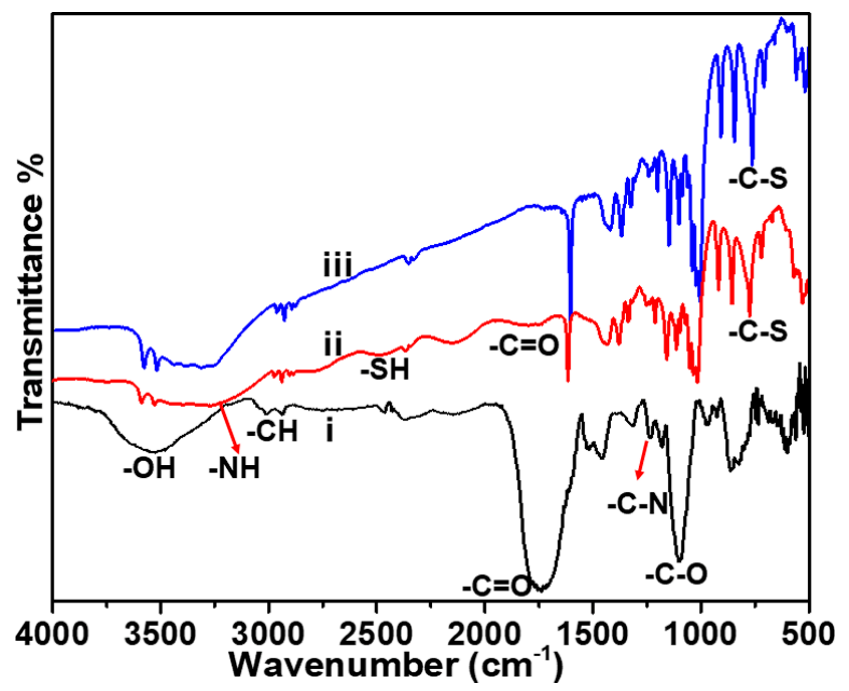

Figure 4. FT-IR spectra of i) red onion leaves extract (Seongnam, South Korea) GCNDs ii) before and iii) after the addition of $\mathrm{Hg}^{2+}$ ions.

\subsection{Optical Properties of GCNDs}

The UV-Vis absorbance spectra of onion leaves extract are shown in Figure 5a. The spectrum shows five bands at 265, 293, 320,342, and $377 \mathrm{~nm}$, which is attributed to characteristic peaks of biomolecules like anthocyanins, quercetin, and kaempferol etc., which are present in the extract and can act as a reducing agent as well as a carbon precursor in the formation of GCNDs. The results are well matched with reported literature [46-48]. Figure 5b,c show the UV-Vis absorbance and PL spectra of the synthesized GCNDs. The UV-Vis absorbance bands at approximately 290 and $340 \mathrm{~nm}$ (attributed to the presence of $\pi-\pi^{*}$ and $n-\pi^{*}$, respectively) are attributed to $C=C$ bonds of the sp ${ }^{2}$ aromatic moiety of the $\mathrm{CDs}$ and to $\mathrm{C}=\mathrm{O}, \mathrm{COOH}$ and $-\mathrm{NH}$ bonds (Figure 5b) [49]. This result indicates that the GSH groups are chelated on the surface of GCNDs, as shown in Scheme 2. Moreover, the inset in Figure 5b clearly shows the orange fluorescent behavior of GCNDs in the absence and presence of UV light. Figure 5c shows that the PL spectra of GCNDs has an emission at $610 \mathrm{~nm}$ when excited at $380 \mathrm{~nm}$. In addition, Figure $5 \mathrm{~d}(\mathrm{i}-\mathrm{iii})$ shows the PL spectra of bare CDs, pure Au clusters, and GCNDs, which have emission peaks at 430,645 , and $610 \mathrm{~nm}$, respectively. The GCNDs are given a blue shift owing to the presence of CD moiety. The fluorescent GCNDs show a quantum yield of $11 \%$. In Figure 6, we show the optimized stability of GCNDs under different conditions. Figure 6a shows that the various excitation (from 360 to $460 \mathrm{~nm}$ ) is dependent on emission peaks. The PL excitation dependent emission spectrum indicates that the PL emission peak exhibited a blue shift transition from 630 to $530 \mathrm{~nm}$ when the excitation wave lengths were from 360 to $460 \mathrm{~nm}$. This shift is mainly attributed due to the presence of carbogenic core moiety. Figure $6 \mathrm{~b}$ shows the $\mathrm{pH}$-dependent fluorescence behavior of GCNDs. The PL spectra are recorded at various $\mathrm{pH}$ values $(2.0,3.0,5.0,6.0,7.5,9.0,10$, and 12$)$. The PL intensity is low at lower $\mathrm{pH}$ values (quenched by as much as $59 \%$ ), however at higher values, PL intensity looks almost the same for $\mathrm{pH}$ values higher than 7 . At lower $\mathrm{pH}$ values, there is competition between protons $\left(\mathrm{H}^{+}\right)$and $\mathrm{Hg}^{2+}$ ions which will lower the probe sensitivity. In contrast, at higher $\mathrm{pH}$ values, the $\mathrm{Hg}^{2+}$ ions can precipitate to $\mathrm{Hg}(\mathrm{OH})^{+}, \mathrm{Hg}(\mathrm{OH})_{2}$, and $\mathrm{Hg}(\mathrm{OH})_{3}{ }^{-}$, which will reduce the sensitivity of the probe [9]. In addition, the stability of GCNDs after various time intervals at room temperature was investigated. As shown in Figure 6c, the PL intensity for 300 days is nearly $92 \%$. The stability of the GCNDs depends on the carbon template which is internally conglomerate with the gold suspension which form stable GCNDs. Owing to the excellent stability of these GCNDs, they appear useful for various biological and catalytic applications. 

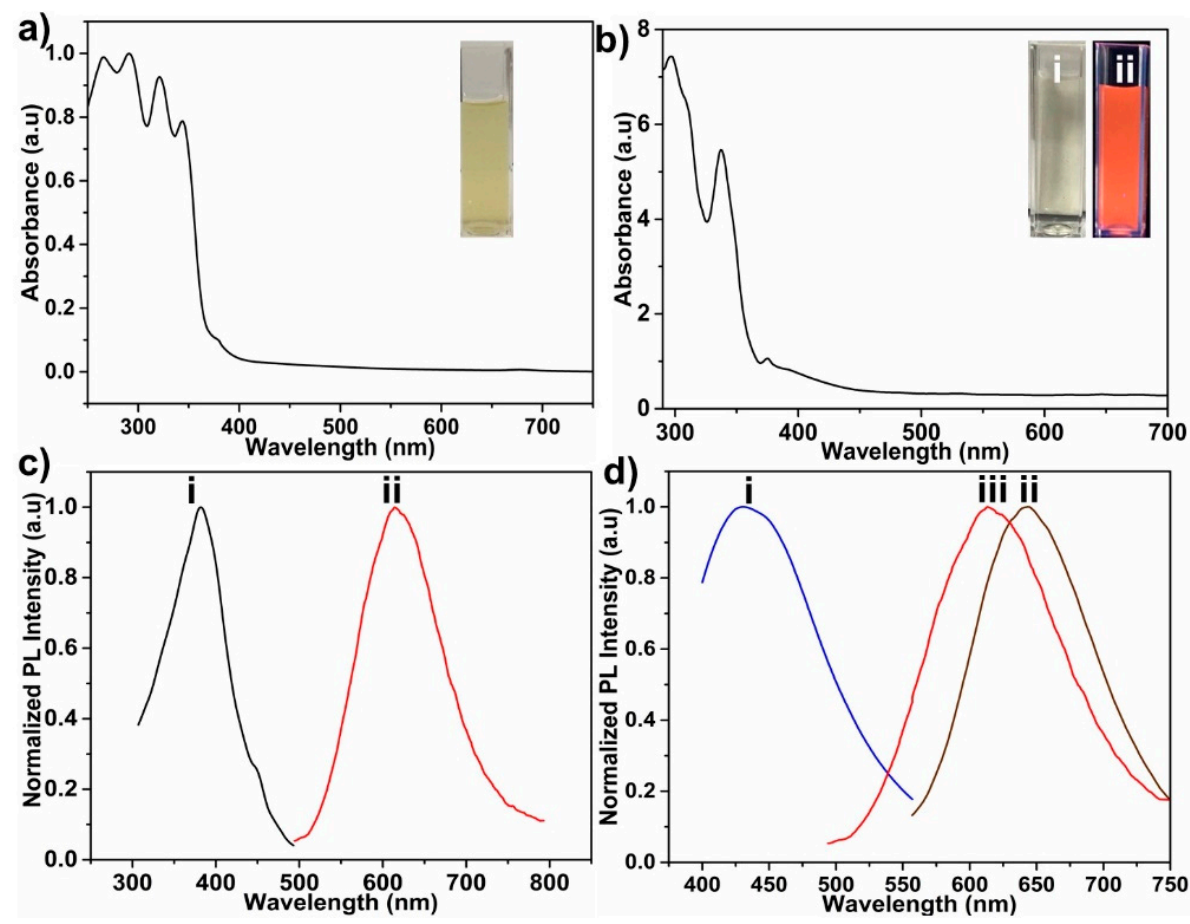

Figure 5. (a) UV-Vis absorption spectra of the red onion leaves extract (inset image is leaves extract) (Seongnam, South Korea), (b) GCNDs and inset image represents (i) is visible light, (ii) is the orange color of GCNDs under UV illumination, (c) PL intensity of GCNDs at (i) exitation $380 \mathrm{~nm}$ and (ii) emission at $610 \mathrm{~nm}$ and (d) PL emission spectra of bare carbon dots (i), pure Au clusters (ii) and GCNDs (iii).
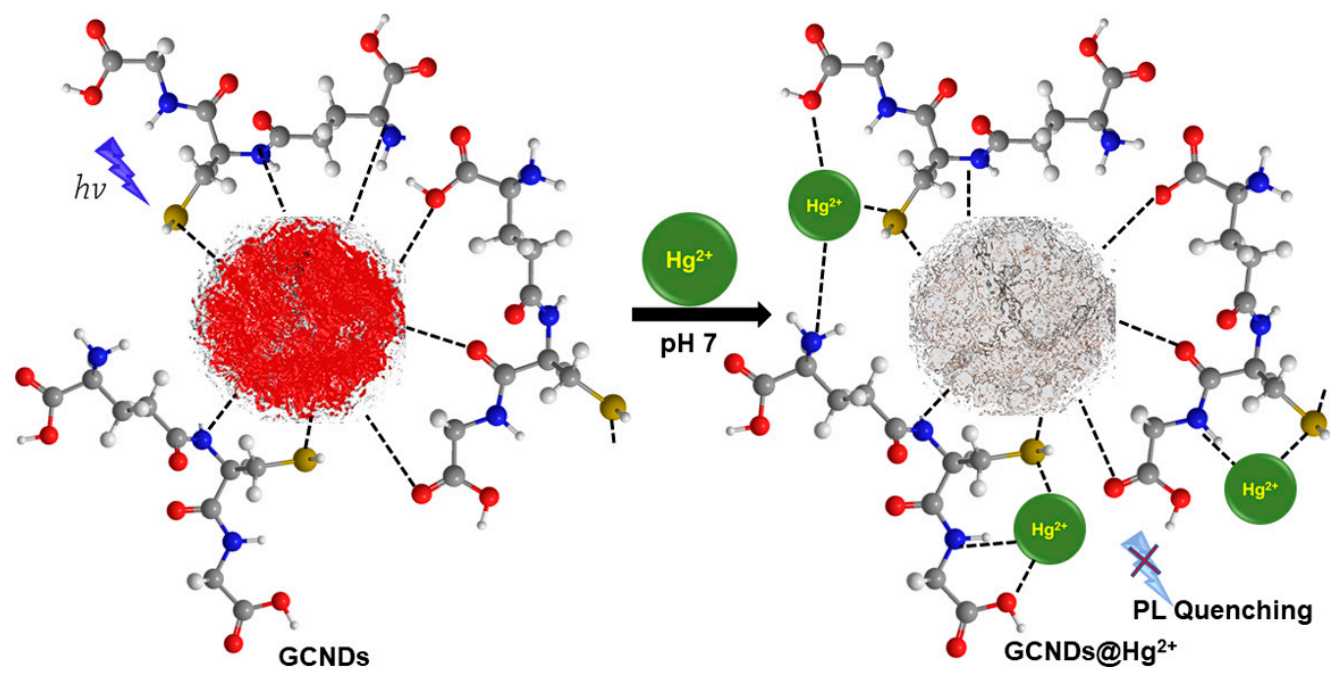

Scheme 2. Schematic representation of the binding and sensing mechanism of the GCNDs for $\mathrm{Hg}^{2+}$ ions. 

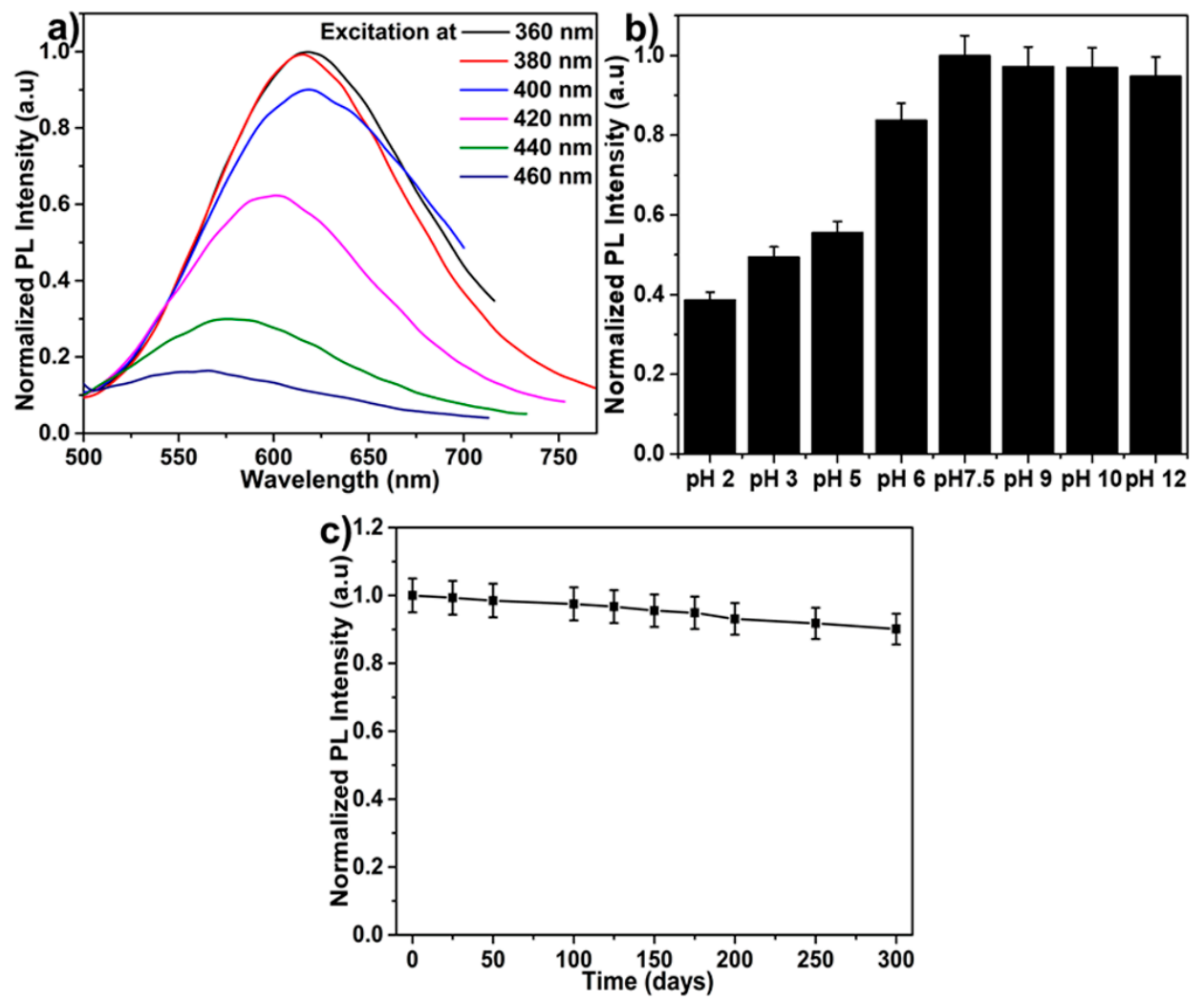

Figure 6. PL (photoluminescence) analysis of GCNDs. (a) different excitation dependent emission spectra, (b) various $\mathrm{pH}$ values, and (c) stability of GCNDs with respect to time.

\subsection{Sensitivity and Selectivity of GCNDs Towards $\mathrm{Hg}^{2+}$ Ions}

The as-synthesized GCNDs were used to determine their effectiveness in the detection of $\mathrm{Hg}^{2+}$. The fluorescence sensor was tested using different concentrations of $\mathrm{Hg}^{2+}(0-70 \mu \mathrm{M})$, as shown in Figure 7a. The PL quenching of GCNDs in the presence of $\mathrm{Hg}^{2+}$ was $95 \%$ upon the addition of $\mathrm{Hg}^{2+}$ ions. The relative changes of fluorescence intensity from the initial intensity $\left(\mathrm{F}_{0} / \mathrm{F}\right)$ at $380 \mathrm{~nm}$, with $\mathrm{Hg}^{2+}$ at $0-70 \mu \mathrm{M}$, are shown Figure $7 \mathrm{~b}$. Depending on the concentration of $\mathrm{Hg}^{2+}$, the fluorescence intensity is gradually quenched and the detection limit is achieved up to $1.3 \mathrm{nM}$, which is much better than the other methods listed in Table 1 [50-55]. This is due to the presence of -SH and amine groups on the GCNDs surface that can react strongly with $\mathrm{Hg}^{2+}$ ions. The limit of detection was determined by using the following equation:

$$
\mathrm{LOD}=3 \times \sigma / \mathrm{m}
$$

where $\sigma$ is the standard deviation of the lowest tested concentration and $m$ is the slope [14]. Based on the XPS and FT-IR results, we were able to identify a clear mechanism. Moreover, the Au nanoclusters and carbon skeleton that form each GCNDs support the functions of the fluorescence resonance energy transfer (FRET) sensor [55]. To determine their selectivity, we investigated the effect of interference ions such as $\mathrm{Fe}^{2+}, \mathrm{Fe}^{3+}, \mathrm{Ni}^{2+}, \mathrm{Ag}^{+}, \mathrm{Cd}^{2+}, \mathrm{Mn}^{2+}, \mathrm{Cr}^{2+}, \mathrm{Ca}^{2+}$, and $\mathrm{Mg}^{2+}$ with concentrations that are two-fold higher than that of the target $\mathrm{Hg}^{2+}(70 \mu \mathrm{M})$ ions. The fluorescence intensity of the GCNDs was quenched $95 \%$ by the $\mathrm{Hg}^{2+}$ ions, whereas the other metal ions did not show any significant fluorescence quenching, as shown in Figure 7c. Along with $\mathrm{Hg}^{2+}$, other soft acid metal ions such as $\mathrm{Ag}^{+}$and $\mathrm{Cd}^{2+}$ were also studied. It is important to note that our probe could distinguish $\mathrm{Hg}^{2+}$ from $\mathrm{Ag}^{+}$and $\mathrm{Cd}^{2+}$. This may be that the $5 \mathrm{~d}$ series of $\mathrm{Hg}^{2+}$ can form a stable amalgam compared to the $4 \mathrm{~d}$ series of $\mathrm{Ag}^{+}$and $\mathrm{Cd}^{2+}$, which is in agreement with the literature [1,56]. In addition, we used the new sensor to detect $\mathrm{Hg}^{2+}$ ions in a river water sample which was collected from the Han River (Seoul, South Korea). The collected water was filtered using a $0.45 \mu \mathrm{m}$ membrane to remove 
impurities and was centrifuged at 20,000 rpm for $30 \mathrm{~min}$ before analysis. For the pre-treated river water, various concentrations of $\mathrm{Hg}^{2+}$ ions $(0-40 \mu \mathrm{M})$ and various interference ions $(100 \mu \mathrm{M})$ were added. Figure 8a shows the PL quenching of GCNDs in the presence of $\mathrm{Hg}^{2+}$ ions, and Figure $8 \mathrm{a}(\mathrm{i}, \mathrm{ii})$ inset photos indicate the images of GCNDs before and after $\mathrm{Hg}^{2+}$ addition under UV illumination. The detection limit is $126 \mathrm{nM}$. Figure $8 \mathrm{~b}$ shows the selectivity of GCNDs. The river water contains various sources of interference, such as halogen ions, carbonates, bicarbonates, phosphates, and some organic dye molecules. The fluorescence intensity of GCNDs in real water is quenched by as much as $80 \%$ of $\mathrm{Hg}^{2+}$ ions. These results reveal that the newly developed GCNDs probe is useful for practical environmental applications.
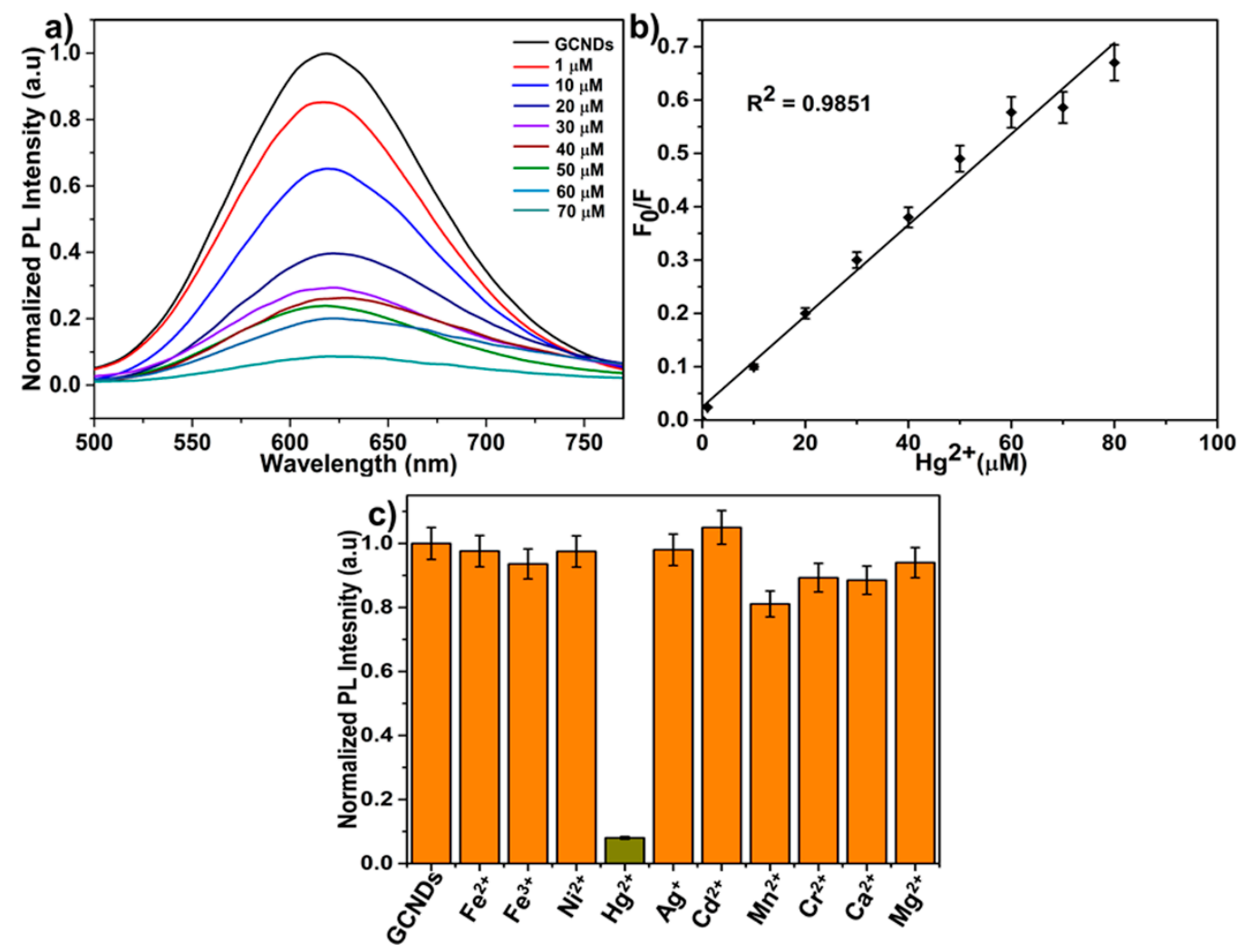

Figure 7. (a) Detection of $\mathrm{Hg}^{2+}$ in different concentrations (b) linear fit of quenched fluorescence intensity as a function of $\mathrm{Hg}^{2+}$ concentration and (c) selectivity study of $\mathrm{Hg}^{2+}$ with different metal ions.

Table 1. Comparison of the present method with other various methods reported in the literature.

\begin{tabular}{|c|c|c|c|}
\hline Nanomaterial & Technique & $\begin{array}{l}\text { Limit of Detection } \\
\text { (LOD) }\end{array}$ & Reference \\
\hline Carbon dots & $\begin{array}{l}\text { FRET (fluorescence resonance } \\
\text { energy transfer) }\end{array}$ & $62 \mathrm{nM}$ & 50 \\
\hline $\begin{array}{l}\text { p-tert-Butylcalixarene Thiospirolactam } \\
\text { Rhodamine B }\end{array}$ & FRET & $9.65 \mathrm{nM}$ & 51 \\
\hline $\begin{array}{l}\text { Dithiothreitol modified carbon dots-gold } \\
\text { nanoclusters }\end{array}$ & Ratiometric fluorescence sensor & $8.7 \mathrm{nM}$ & 34 \\
\hline rGO-SH/Au-NPs & Electrochemical sensor & $200 \mathrm{nM}$ & 52 \\
\hline Nitrogen and sulfur doped carbon dots & Fluorescence sensor & $8 \mathrm{nM}$ & 53 \\
\hline $\begin{array}{l}\text { Aptamers-Functionalized Upconversion } \\
\text { Nanoparticles and Gold Nanoparticles }\end{array}$ & FRET & $60 \mathrm{nM}$ & 54 \\
\hline $\mathrm{Au} / \mathrm{C}$ Nanodots & Fluorescence sensor & $1.3 \mathrm{nM}$ & Current work \\
\hline
\end{tabular}



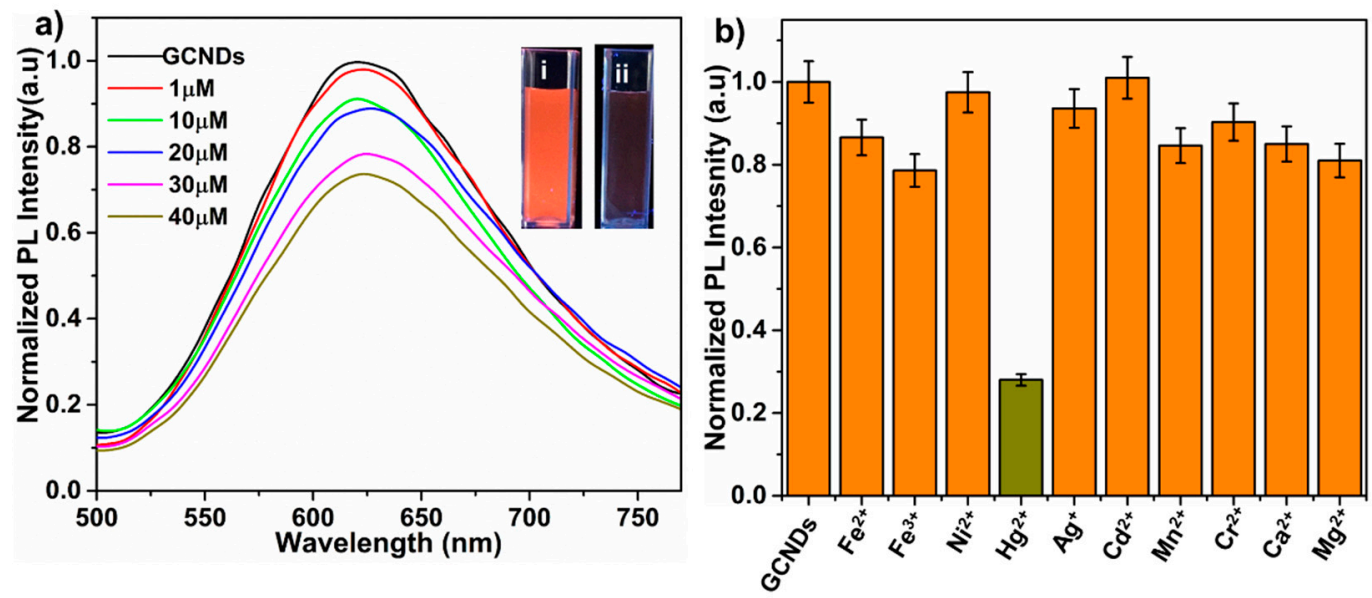

Figure 8. $\mathrm{Hg}^{2+}$ ion sensing in river water sample by GCNDs. (a) detection of $\mathrm{Hg}^{2+}$ in different concentration (inset photos indicate the images of GCNDs before and after $\mathrm{Hg}^{2+}$ addition under UV illumination) and (b) comparison study of $\mathrm{Hg}^{2+}$ with different metal ions.

\subsection{Reproducibility Study}

For confirmation of the reproducibility of the material synthesis and its application, we have collected the red onion leaves from various places (Daegu and Incheon, South Korea) and the extract was prepared using the same method. The prepared extract was characterized by using FT-IR and UV-Vis absorption spectroscopic techniques. Figure S1(i,ii) shows that the FT-IR spectra of onion leaves extract for both samples exhibit the major peaks at $\sim 3500, \sim 1700$, and $\sim 1070 \mathrm{~cm}^{-1}$, which is attributed to the hydroxyl $(-\mathrm{OH})$, carbonyl $(-\mathrm{C}=\mathrm{O})$, and ether $(-\mathrm{C}-\mathrm{O})$, and similar groups are presented in both samples. The functional groups may have derived from the backbone of the following molecules; flavonoids, polysaccharides, anthocyanins, gallic acid, etc. that can play a key role in the formation of nanoparticles. In addition, the UV-Vis absorbance spectra of these onion leaf extracts are shown in Figure S2(i,ii). The absorption curve is similar to the spectra in Figure 5a, indicating that the extract may have a composition of biomolecules like anthocyanins, quercetin, and kaempferol etc. The presented moieties can act as a reducing agent as well as a carbon precursor in the formation of GCNDs. Moreover, Figure S3(i,ii) shows the UV-Vis absorption spectra of the synthesized GCNDs. The UV-Vis absorbance bands are approximately similar to the bands that are shown in (Figure 5b). The inset in Figure S3 clearly shows the orange fluorescent behavior of GCNDs in the absence and presence of UV light. Finally, we have observed quenching behavior of the re synthesized GCNDs towards the target $\mathrm{Hg}^{2+}$ ion; the result is shown in Figure S4a,b. These results confirm the regeneration of the extract as well as synthesized material by red onion species collected from various cultivated areas. This result indicates that the red onion cultivated in different places also shows similar results and therefore, the red onion extract can have reproducibility for this application.

\subsection{Quenching Mechanism of GCNDs by $\mathrm{Hg}^{2+}$ Ions}

According to Pearson's HSAB theory, soft acid groups can rapidly react with $\mathrm{Hg}^{2+}$ ions. Therefore, the high selectivity is attributed to the presence of soft base (-SH), which is highly reactive towards soft acid (in this case, $\mathrm{Hg}^{2+}$ ). Moreover, after treatment of $\mathrm{Hg}^{2+}$ ions, the high-resolution XPS spectra of S-2p and N-1s reveal that peaks from 164.5 and $400.5 \mathrm{eV}$ shifted to 399.2 and $163.9 \mathrm{eV}$, as shown in Figure $3 \mathrm{~d}(\mathrm{ii}), \mathrm{f}(\mathrm{ii})$. This is due to electron transfer between $-\mathrm{SH}$ and $\mathrm{Hg}^{2+}$ ions, as shown in Scheme 2, in which case the PL intensity is quenched. A high-resolution spectrum of mercury shows peaks at 100.68 and $104.48 \mathrm{eV}$, which represent $\mathrm{Hg}-4 \mathrm{f}-7 / 2$ and $\mathrm{Hg}-4 \mathrm{f}-5 / 2$, respectively (Figure $3 \mathrm{~g}$ ). In addition, the FT-IR peaks at 1753, 1160 are shifted to $1708,1146 \mathrm{~cm}^{-1}$, and the peak at $2528 \mathrm{~cm}^{-1}$ almost disappears, which confirms that $-\mathrm{C}=\mathrm{O},-\mathrm{C}-\mathrm{N}$, and $-\mathrm{SH}$ groups are strongly attracted to the target $\mathrm{Hg}^{2+}$ ions that are shown in Figure 4(iii). This result concurs with those reported in the literature [57]. 


\section{Conclusions}

In this work, we developed an eco-friendly method for the synthesis of $\mathrm{Au} / \mathrm{C}$ nanodots (GCNDs) using waste red onion leaves extract. Onions are the second most cultivated vegetable crop in the world. These are an abundant source of many flavonoids and phenolic compounds which can act as a reducing, stabilizing agent and carbon precursor. The synthesized GCNDs showed a uniform particle size of $\sim 2 \mathrm{~nm}$, as confirmed by HRTEM, STEM-EDS elemental mapping and AFM analysis. The surface functional groups were identified from FT-IR and XPS results. The GCNDs showed a strong orange fluorescence in the UV-Visible spectrometry. The developed GCNDs were applied as a fluorescent probe for the detection of toxic $\mathrm{Hg}^{2+}$ ions in water. Owing to the carbon precursor, the GCNDs were highly stable up to 300 days and showed an excellent detection limit of $\mathrm{Hg}^{2+}$ ions (as low as $1.3 \mathrm{nM}$ ). This detection limit is one of the lowest among the reported materials. Owing to the -SH functional groups, the GCNDs showed high selectivity towards $\mathrm{Hg}^{2+}$ ions, even in the presence of interference. The detailed mechanism is clearly explained using XPS and FT-IR techniques. Moreover, the newly developed GCNDs were used successfully to test a real river water sample and they provided a detection limit of $126 \mathrm{nM}$. We have also regenerated the extract as well as synthesized material by red onion leaves that were collected from various cultivated areas. These newly developed GCNDs may also be useful for other applications such as catalysis, electrochemistry, and biomedicine.

Supplementary Materials: The following are available online at http:/ /www.mdpi.com/2079-4991/9/2/245/s1: Figure S1: FT-IR spectra of red onion leaves extract obtained from (i) Daegu and (ii) Incheon, South Korea; Figure S2: UV-Vis absorption spectra of the red onion leaves extract obtained from (i) Daegu and (ii) Incheon, South Korea; Figure S3: UV-Vis absorption spectra of GCNDs by various red onion leaves extract obtained from (i) Daegu and (ii) Incheon, South Korea; Figure S4: $\mathrm{Hg}^{2+}$ ion sensing by GCNDs synthesized from various red onion leaves extract obtained from a) Daegu and b) Incheon, South Korea.

Author Contributions: Conceptualization, S.V., S.G.; Methodology, S.G., R.S.; Resources, S.V., S.G.; Writing-Original draft preparation S.V., S.G.; Review and editing, S.V., J.K., M.-H.L., and K.Y.; Project Administration, S.V., S.G., M.-H.L., and K.Y.

Acknowledgments: This research was supported by the National Research Foundation of Korea (NRF) grant which was funded by the Korea Government (MSIP) (No.2017R1A2B4004700). This work was supported by the Ministry of Trade, Industry, and Economy (Grant no. 10062995). This work was also supported by a National Research Foundation of Korea (NRF) grant which was funded by the Ministry of Science and ICT (NRF-2017R1C1B5076834, S.V.).

Conflicts of Interest: The authors declare no conflict of interest.

\section{References}

1. Govindaraju, S.; Puthiaraj, P.; Lee, M.H.; Yun, K. Photoluminescent AuNCs@ Uio-66 for Ultrasensitive Detection of Mercury in Water Samples. ACS Omega 2018, 3, 12052-12059. [CrossRef]

2. Venkateswarlu, S.; Panda, A.; Kim, E.; Yoon, M. Biopolymer-Coated Magnetite Nanoparticles and Metal-Organic Framework Ternary Composites for Cooperative Pb (II) Adsorption. ACS Appl. Nano Mater. 2018, 1, 4198-4210. [CrossRef]

3. Kim, S.; Chu, K.H.; Al-Hamadani, Y.A.J.; Park, C.M.; Jang, M.; Kim, D.H.; Yu, M.; Heo, J.; Yoon, Y. Removal of Contaminants of Emerging Concern by Membranes in Water and Wastewater: A Review. Chem. Eng. J. 2017, 335, 896-914. [CrossRef]

4. Venkateswarlu, S.; Lee, D.; Yoon, M. Bioinspired 2D-Carbon Flakes and $\mathrm{Fe}_{3} \mathrm{O}_{4}$ Nanoparticles Composite for Arsenite Removal. ACS Appl. Mater. Interfaces 2016, 8, 23876-23885. [CrossRef] [PubMed]

5. Ali, S.A.; Mazumder, M.A.J. A New Resin Embedded With Chelating Motifs of Biogenic Methionine for the Removal of Hg (II) at ppb Levels. J. Hazard. Mater. 2018, 350, 169-179. [CrossRef] [PubMed]

6. Maia, L.F.O.; Hott, R.C.; Ladeira, P.C.C.; Batista, B.L.; Andrade, T.G.; Santos, M.S.; Faria, M.C.S.; Oliveira, L.C.A.; Monteiro, D.S.; Pereira, M.C.; et al. Simple Synthesis and Characterization of 1-Cystine Functionalized $\delta$-FeOOH for Highly Efficient $\mathrm{Hg}$ (II) Removal From Contamined Water and Mining Waste. Chemosphere 2019, 215, 422-431. [CrossRef] [PubMed] 
7. Zhao, Y.; Yang, J.; Ma, S.; Zhang, S.; Liu, H.; Gong, B.; Zhang, J.; Zheng, C. Emission Controls of Mercury and Other Trace Elements During Coal Combustion in China: A Review. Int. Geol. Rev. 2018, 60, 638-670. [CrossRef]

8. Vikrant, K.; Kim, K.H. Nanomaterials for the Adsorptive Treatment of Hg (II) Ions from Water. Chem. Eng. J. 2019, 358, 264-282. [CrossRef]

9. Venkateswarlu, S.; Yoon, M. Surfactant-free Green Synthesis of $\mathrm{Fe}_{3} \mathrm{O}_{4}$ Nanoparticles Capped with 3, 4-Dihydroxyphenethylcarbamodithioate: Stable Recyclable Magnetic Nanoparticles for the Rapid and Efficient Removal of Hg (II) Ions from Water. Dalton Trans. 2015, 44, 18427-18437. [CrossRef] [PubMed]

10. Liu, H.; Zhao, Y.; Zhou, Y.; Chang, L.; Zhang, J. Removal of Gaseous Elemental Mercury by Modified Diatomite. Sci. Total Environ. 2019, 652, 651-659. [CrossRef]

11. Liu, X.; Tang, Y.; Wang, L.; Zhang, J.; Song, S.; Fan, C.; Wang, S. Optical Detection of Mercury (II) in Aqueous Solutions by Using Conjugated Polymers and Label-free Oligonucleotides. Adv. Mater. 2007, 19, 1471-1474. [CrossRef]

12. Zhuang, Y.; Zhao, M.; He, Y.; Cheng, F.; Chen, S. Fabrication of ZnO/rGO/PPy Heterostructure for Electrochemical Detection of Mercury ion. J. Electroanal. Chem. 2018, 826, 90-95. [CrossRef]

13. Rout, K.; Manna, A.K.; Sahu, M.; Patra, G.K. A guanidine Based bis Schiff Base Chemosensor for Colorimetric Detection of $\mathrm{Hg}$ (II) and Fluorescent Detection of Zn (II) ions. Inorganica Chim. Acta 2019, 486, 733-741. [CrossRef]

14. Venkateswarlu, S.; Viswanath, B.; Reddy, A.S.; Yoon, M. Fungus-derived Photoluminescent Carbon Nanodots for Ultrasensitive Detection of $\mathrm{Hg}^{2+}$ Ions and Photoinduced Bactericidal Activity. Sens. Actuator B Chem. 2017, 258, 172-183. [CrossRef]

15. Shahat, A.; Elsalam, S.A.; Herrero-Martínez, J.M.; Simó-Alfonso, E.F.; Ramis-Ramos, G. Optical Recognition and Removal of $\mathrm{Hg}$ (II) Using a New Self-Chemosensor Based on a Modified Amino-Functionalized Al-MOF. Sens. Actuator B Chem. 2017, 253, 164-172. [CrossRef]

16. Borthakur, P.; Darabdhara, G.; Das, M.R.; Boukherroub, R.; Szunerits, S. Solvothermal Synthesis of $\mathrm{CoS} /$ Reduced Porous Graphene Oxide Nanocomposite for Selective Colorimetric Detection of Hg (II) Ion in Aqueous Medium. Sens. Actuator B Chem. 2017, 244, 684-692. [CrossRef]

17. Sareen, D.; Kaur, P.; Singh, K. Strategies in Detection of Metal Ions Using Dyes. Coordin. Chem. Rev. 2014, 265, 125-154. [CrossRef]

18. Hande, P.E.; Samui, A.B.; Kulkarni, P.S. Selective Nanomolar Detection of Mercury Using Coumarin Based Fluorescent Hg (II)-Ion Imprinted Polymer. Sens. Actuator B Chem. 2017, 246, 597-605. [CrossRef]

19. Rao, L.; Tang, Y.; Lu, H.; Yu, S.; Ding, X.; Xu, K.; Li, Z.; Zhang, J.Z. Highly Photoluminescent and Stable $\mathrm{N}$-Doped Carbon Dots as Nanoprobes for $\mathrm{Hg}^{2+}$ Detection. Nanomaterials 2018, 8, 900. [CrossRef]

20. Baig, M.M.F.; Chen, Y.C. Bright Carbon dots as Fluorescence Sensing Agents for Bacteria and Curcumin. J. Colloid Interface Sci. 2017, 501, 341-349. [CrossRef]

21. Gaddam, R.R.; Mukherjee, S.; Punugupati, N.; Vasudevan, D.; Patra, C.R.; Narayan, R.; Kothapalli, R.V. Facile Synthesis of Carbon Dot and Residual Carbon Nanobeads: Implications for Ion Sensing, Medicinal and Biological Applications. Mater. Sci. Eng. C 2017, 73, 643-652. [CrossRef] [PubMed]

22. Amjadi, M.; Shokri, R.; Hallaj, T. Interaction of Glucose-Derived Carbon Quantum Dots with Silver and Gold Nanoparticles and Its Application for the Fluorescence Detection of 6-Thioguanine. Luminescence 2017, 32, 292-297. [CrossRef] [PubMed]

23. Zhang, Y.; Zhang, J.; Zhang, J.; Lin, S.; Huang, Y.; Yuan, R.; Liang, X.; Xiang, W. Intense Enhancement of Yellow Luminescent Carbon Dots Coupled with Gold Nanoparticles Toward White LED. Dyes Pigm. 2017, 140, 122-130. [CrossRef]

24. Chen, T.; Sheng, A.; Hu, Y.; Mao, D.; Ning, L.; Zhang, J. Modularization of Three-Dimensional Gold Nanoparticles/Ferrocene/Liposome Cluster for Electrochemical Biosensor. Biosens. Bioelectron. 2019, 124, 115-121. [CrossRef] [PubMed]

25. Yu, Y.; New, S.Y.; Xie, J.; Su, X.; Tan, Y.N. Protein-Based Fluorescent Metal Nanoclusters for Small Molecular Drug Screening. Chem. Commun. 2014, 50, 13805-13808. [CrossRef] [PubMed]

26. Kraszkiewicz, P.; Mista, W. Thermally Stable SBA-15 Supported sub-2 nm Gold Clusters, Highly Active in Room Temperature CO Oxidation: Effect of Thermal Pretreatment. Catal. Commun. 2018, 110, 14-17. [CrossRef] 
27. Govindaraju, S.; Ankireddy, S.R.; Viswanath, B.; Kim, J.; Yun, K. Fluorescent Gold Nanoclusters for Selective Detection of Dopamine in Cerebrospinal Fluid. Sci. Rep. 2017, 7, 40298. [CrossRef] [PubMed]

28. Li, H.; Kang, Z.; Liu, Y.; Lee, S.T. Carbon Nanodots: Synthesis, Properties and Applications. J. Mater. Chem. 2012, 22, 24230-24253. [CrossRef]

29. Chou, S.S.; De, M.; Luo, J.; Rotello, V.M.; Huang, J.; Dravid, V.P. Nanoscale Graphene Oxide (nGO) as Artificial Receptors: Implications for Biomolecular Interactions and Sensing. J. Am. Chem. Soc. 2012, 134, 16725-16733. [CrossRef] [PubMed]

30. Lei, Z.; Wang, Q.M. Homo and Heterometallic Gold (I) Clusters with Hypercoordinated Carbon. Coordin. Chem. Rev. 2019, 378, 382-394. [CrossRef]

31. Yang, G.; Zhang, H.; Wang, Y.; Liu, X.; Luo, Z.; Yao, J. Enhanced Stability and Fluorescence of Mixed-Proteins-Protected Gold/Silver Clusters Used for Mercury Ions Detection. Sens. Actuator B Chem. 2017, 251, 773-780. [CrossRef]

32. Li, L.; Zhang, L.; Lou, T.; Chen, Z. Iodide-Responsive Cu@ Au Nanoparticle-Based Colorimetric Assay for Sensitive Mercury (II) Detection. Sens. Actuator B Chem. 2017, 252, 663-670. [CrossRef]

33. Verma, S.; Rao, B.T.; Srivastava, A.K.; Patel, H.S.; Satapathy, S.; Joshi, M.P.; Sahu, V.K.; Kukreja, L.M. Studies on Interdependent Optical Properties of Rhodamine 6G Dye and Gold Nanoparticles at Different Dilutions of Aqueous Solutions. J. Lumin. 2014, 155, 156-164. [CrossRef]

34. Liu, W.; Wang, X.; Wang, Y.; Li, J.; Shen, D.; Kang, Q.; Chen, L. Ratiometric Fluorescence Sensor Based on Dithiothreitol Modified Carbon Dots-Gold Nanoclusters for the Sensitive Detection of Mercury Ions in Water Samples. Sens. Actuator B Chem. 2018, 262, 810-817. [CrossRef]

35. Abdelhamid, H.N.; Talib, A.; Wu, H.F. One Pot Synthesis of Gold-Carbon Dots Nanocomposite and Its Application for Cytosensing of Metals for Cancer Cells. Talanta 2017, 166, 357-363. [CrossRef] [PubMed]

36. Jaiswal, N.; Kumar, D.; Rizvi, S.I. Red Onion Extract (Allium cepa L.) Supplementation Improves Redox Balance in Oxidatively Stressed Rats. Food Sci. Hum. Well. 2013, 2, 99-104. [CrossRef]

37. Pérez-Gregorio, R.M.; García-Falcón, M.S.; Simal-Gándara, J.; Rodrigues, A.S.; Almeida, D.P. Identification and quantification of flavonoids in traditional cultivars of red and white onions at harvest. J. Food Compos. Anal. 2010, 23, 592-598. [CrossRef]

38. Gitîn, L.; Dinicâ, R.; Neagu, C.; Dumitrascu, L. Sulfur Compounds Identification and Quantification from Allium spp. Fresh Leaves. J. Food Drug Anal. 2014, 22, 425-430. [CrossRef]

39. Zhang, S.L.; Deng, P.; Xu, Y.C.; Lu, S.W.; Wang, J.J. Quantification and Analysis of Anthocyanin and Flavonoids Compositions, and Antioxidant Activities in Onions with Three Different Colors. J. Integr. Agric. 2016, 15, 2175-2181. [CrossRef]

40. Khalilzadeh, M.A.; Borzoo, M. Green Synthesis of Silver Nanoparticles Using Onion Extract and Their Application for the Preparation of a Modified Electrode for Determination of Ascorbic acid. J. Food Compos. Anal. 2016, 24, 796-803. [CrossRef]

41. Liu, D.; Wu, F. Biosynthesis of Pd Nanoparticle Using Onion Extract for Electrochemical Determination of Carbendazim. Int. J. Electrochem. Sci. 2017, 12, 2125-2134. [CrossRef]

42. Yu, J.; Gao, L.Z.; Li, X.L.; Wu, C.; Gao, L.L.; Li, C.M. Porous Carbons Produced by the Pyrolysisof Green Onion Leaves and Their Capacitive Behavior. New Carbon Mater. 2016, 31, 475-484. [CrossRef]

43. Donner, H.; Gao, L.; Mazza, G. Separation and Characterization of Simple and Malonylated Anthocyanins in Red Onions, Allium cepa L. Food Res. Int. 1997, 30, 637-643. [CrossRef]

44. Venkateswarlu, S.; Yoon, M. Core-Shell Ferromagnetic Nanorod Based on Amine Polymer Composite $\left(\mathrm{Fe}_{3} \mathrm{O}_{4} @ \mathrm{DAPF}\right)$ for Fast Removal of Pb (II) from Aqueous Solutions. ACS Appl. Mater. Interfaces 2015, 7, 25362-25372. [CrossRef] [PubMed]

45. Zhu, D.Y.; Ma, Y.L.; Wang, C.H.; Wang, H.; Ren, Y.F.; Zhang, J.G.; Thakur, K.; Wei, Z.J. Insights into Physicochemical and Functional Properties of Polysaccharides Sequentially Extracted from Onion (Allium cepa L.). Int. J. Biol. Macromol. 2017, 105, 1192-1201. [CrossRef] [PubMed]

46. Demir, T.; Gunesli, Z.; Sonmez, F.; Bilen, C.; Yavuz, E.; Gencer, N. Inhibition of Carbonic Anhydrase I and II with Total Anthocyanins Extracted from Sweet Cherry Cultivars. Environ. Eng. Manag. J. 2015, 14, 935-941. [CrossRef]

47. Telange, D.R.; Patil, A.T.; Tatode, A.; Bhoyar, B. Development and Validation of UV Spectrophotometric Method for the Estimation of Kaempferol in Kaempferol: Hydrogenated Soy Phosphatidylcholine (HSPC) complex. Pharm. Meth. 2014, 5, 34-38. [CrossRef] 
48. Sonmezoglu, S.; Akyurek, C.; Akin, S. High-Efficiency Dye-Sensitized Solar Cells Using Ferrocene-Based Electrolytes and Natural Photosensitizers. J. Phys. D Appl. Phys. 2012, 45, 425101. [CrossRef]

49. He, Y.S.; Pan, C.G.; Cao, H.X.; Yue, M.Z.; Wang, L.; Liang, G.X. Highly Sensitive and Selective Dual-Emission Ratiometric Fluorescence Detection of Dopamine Based on Carbon Dots-Gold Nanoclusters Hybrid. Sens. Actuator B Chem. 2018, 265, 371-377. [CrossRef]

50. Tabaraki, R.; Sadeghinejad, N. Microwave Assisted Synthesis of Doped Carbon Dots and Their Application as Green and Simple Turn Off-on Fluorescent Sensor for Mercury (II) and Iodide in Environmental Samples. Ecotox. Environ. Safe 2018, 153, 101-106. [CrossRef]

51. Anandababu, A.; Anandan, S.; Ashokkumar, M. A Simple Discriminating p-tert-Butylcalix[4]arene Thiospirolactam Rhodamine B Based Colorimetric and Fluorescence Sensor for Mercury Ion and Live Cell Imaging Applications. Chem. Sel. 2018, 3, 4413-4420. [CrossRef]

52. Devi, N.R.; Sasidharan, M.; Sundramoorthy, A.K. Gold Nanoparticles-Thiol-Functionalized Reduced Graphene Oxide Coated Electrochemical Sensor System for Selective Detection of Mercury Ion. J. Electrochem. Soc. 2018, 165, B3046-B3053. [CrossRef]

53. Tabaraki, R.; Abdi, O. Green and Simple Turn off/on Fluorescence Sensor for Mercury (II), Cysteine and Histidine. J. Mol. Liq. 2018, 251, 77-82. [CrossRef]

54. Liu, Y.; Ouyang, Q.; Li, H.; Chen, M.; Zhang, Z.Z.; Chen, Q. A Turn-on Fluoresence Sensor for $\mathrm{Hg}^{2+}$ in Food Based on FRET between Aptamers-Functionalized Upconversion Nanoparticles and Gold Nanoparticles. J. Agric. Food Chem. 2018, 66, 6188-6195. [CrossRef] [PubMed]

55. Ju, E.; Liu, Z.; Du, Y.; Tao, Y.; Ren, J.; Qu, X. Heterogeneous Assembled Nanocomplexes for Ratiometric Detection of Highly Reactive Oxygen Species in Vitro and in Vivo. ACS Nano 2014, 8, 6014-6023. [CrossRef] [PubMed]

56. Guo, W.; Yuan, J.; Wang, E. Oligonucleotide-stabilized Ag Nanoclusters as Novel Fluorescence Probes for the Highly Selective and Sensitive Detection of the Hg2+ Ion. Chem. Commun. 2009, 23, 3395-3397. [CrossRef] [PubMed]

57. Zhang, B.H.; Wu, F.Y.; Wu, Y.M.; Zhan, X.S. Fluorescent Method for the Determination of Sulfide Anionwith ZnS: Mn Quantum Dots. J. Fluoresc. 2010, 20, 243-250. [CrossRef] [PubMed] 